\title{
Prenatal alcohol and offspring development: the first fourteen years
}

\author{
Ann P. Streissguth* ${ }^{a, b}$, Helen M. Barr ${ }^{a, b}$, Paul D. Sampson ${ }^{b . c}$, Fred L. Bookstein ${ }^{d}$ \\ "Department of Psychiatry and Behavioral Sciences, ${ }^{b}$ Fetal Alcohol and Drug Unit, "Department of Statistics. Intvervity of Washington. \\ Seattle, WA 98195, LSA \\ ${ }^{\mathrm{S}}$ Center for Human Growth and Development. Universit? of Michigan. Ann Arhor. MI 48104 (SA
}

Received 13 December 1993; accepted 8 August 1994

\begin{abstract}
This report summarizes findings from a prospective longitudinal study of the effects of prenatal alcohol exposure on a birth cohort of 500 offspring selected from 1529 consecutive pregnant women in prenatal care by mid-pregnancy at two representative community hospitals. Effects of prenatal alcohol observable on size measures at birth were insignificant after 8 months. Morphometric analysis of facial features identified effects only at the very highest alcohol exposure levels. By contrast, dose-dependent effects on neurobehavioral function from birth to 14 years have been established using partial least squares (PLS) methods jointly analysing multiple measures of both alcohol dose and outcome. Particularly salient effects included problems with attention. speed of information processing, and learning problems, especially arithmetic.
\end{abstract}

Keywords: Fetal alcohol effects; Fetal alcohol syndrome; Alcohol teratology; Longitudinal research: Learning problems: Partial least squares

\section{Introduction}

The Seattle Study on Alcohol and Pregnancy was initiated in 1974 to examine the long-term effects of prenatal alcohol exposure. At the time the study began. Fetal Alcohol Syndrome (FAS) had just been identified (Lemoine et al., 1968; Jones and Smith, 1973; Jones et al., 1973). One additional study of children of alcoholic mothers had indicated that they were at risk for growth deficiency, lowered IQ, and physical anomalies associated with FAS, by comparison with an extensive wellmatched control group (Jones et al., 1974). Our goal was to see how these findings extended to the whole range of prenatal exposure, but focusing on the moderate range of doses characteristic of 'social drinking'.

\section{Rationale, methods and analyses}

Although there was little evidence in 1974 that alcohol was teratogenic, our study was designed in keeping with the principles of teratogenic theory (Wilson, 1977). Dose, timing, and conditions of exposure were measured as precisely as possible. Three types of teratogenic outcome were examined - deficits in growth, morphology, and function - all of which were apparent in children with FAS. The functional outcomes included age-appropriate neurobehavioral and performance measures. Careful measures of dose and conditions of exposure were combined with sensitive outcome measures and assessment of many potential covariates.

The study design is prospective, longitudinal, and population-based for greater generalizability (see Fig. 1). Beginning with standardized maternal interviews at the fifth month of pregnancy, and following the same birth cohort of children through the first 14 years of life 
with a high follow-up rate, has permitted evaluation of the long-term effects of prenatal alcohol exposure on children's health and development.

Several factors contribute to the ability of this study to detect effects where they exist. The study began at a time when alcohol was not known to have adverse effects on offspring, so that drinking was commonplace among pregnant women, who had less reason to minimize their reported consumption than they would have today. Drinking and heavy drinking among Seattle women in 1974/75 were not limited to just one end of the socio-economic scale, and use of other drugs was generally low. Certain aspects of the sampling procedures precluded the serious confounding of alcohol with other risk factors such as poor prenatal care that would have made detection of alcohol effects difficult. Selection of a cohort of approximately 500 offspring born to the 1529 screening-study mothers enabled us to retain all the heavier-exposed offspring within a cohort of more manageable size. Stratification of the follow-up sample for smoking across drinking levels permitted separation of alcohol effects from those of smoking. The recruitment criteria required that all women be interviewed by the fifth month of pregnancy in order to assure that all had reasonable prenatal care, and that alcohol use was assessed at a standard gestational age.

Sample selection was biphasic. First, the screening cohort of 1529 pregnant women was drawn consecutively from two Seattle hospitals that together reflected the demographic characteristics of Seattle in 1974/75. The maternal interviews were confidential, conducted in private, and covered many aspects of prenatal life that might have contributed to the health and welfare of the offspring (Streissguth et al., 1981, 1993). The follow-up cohort of approxinately 500 infants was selected at delivery based on the maternal drinking and smoking data obtained at mid-pregnancy in the screening study. Table 1 shows the priority system used to select infants of the heaviest drinking mothers from the screening study into the follow-up cohort.

The self-reported alcohol use by these mothers was representative of the general Seattle population of pregnant women all receiving good prenatal care by midpregnancy at a time before women knew that it was inadvisable to drink during pregnancy. At that time, approximately $80 \%$ of women from this population reported some alcohol use during pregnancy. In the stratified cohort sample, the mothers who drank averaged over one drink per day of beer, wine, or liquor before they knew they were pregnant but less than one drink per day at mid-pregnancy. Although they drank on average on only 9 occasions per month at midpregnancy, $39 \%$ of the drinking mothers had a 'binge' pattern of use indicating 5 or more drinks per occasion in the period prior to pregnancy recognition and $25 \%$ had this pattern in mid-pregnancy. Only 8 mothers reported any major alcohol problems. The findings represent group effects and should not be interpreted for individuals.

The primary independent variable, alcohol, was assessed via a Quantity-Frequency-Variability (QFV) interview (Cahalan et al., 1969) incorporating supplemental questions about higher levels of drinking, intoxications, and problems with drinking. Drinking during two time periods was assessed: during pregnancy (D), and prior to pregnancy or pregnancy recognition (P) (see Streissguth et al., 1993, for details). Alcohol use was quantified in several different dimensions. These are quite highly correlated, and should not be considered as independent measures of exposure. Table 2 lists the seven alcohol scores used in the analyses along with distribution statistics for each score from the longitudinal sample described by Streissguth et al. (1993). They include: an AA score (average ounces of absolute alcohol per day); a categorical QFV score incorporating volume and pattern of use; and three distinct measures of massed or binge-drinking (ADOCC - average drinks per drinking occasion; MAX - maximum drinks any drinking occasion; and BINGE - a dichotomous score reflecting 5 or more drinks on any drinking occasion). These scores were all obtained for the two time periods (P and D). Two summary scores were also obtained: ORDEXC (ordered exposure categories), an a priori 'risk' score that incorporates exposure from both periods; and abstainer, an indicator of absence of alcohol use during both periods considered. The majority of the mothers were white, married and middle class, although the sample contained a broad range of socioeconomic and racial groups, as was characteristic of Seattle mothers (see Table 3 ). Only $8 \%$ of the mothers were receiving welfare support. As Table 3 indicates, the demographic characteristics of the screening sample were very similar to those of the follow-up cohort.

The follow-up cohort of approximately 500 subjects was examined on day 1 and day 2 of life, 8 and 18 months, and 4, 7, and 14 years, and teacher evaluations were obtained at 8 and 11 years (see Fig. 1). All examinations were conducted 'blind' without examiner knowledge about exposure history, living conditions, or previous examination scores. The sample was successfully maintained over this 15 -year period by extensive tracing and outreach activity (Streissguth and Giunta, 1992). Success of follow-up of the entire cohort at each age has been exceptional and there has been no differential loss of heavily exposed subjects. At the 14year examination, $82 \%$ of the original cohort were examined; this was $93 \%$ of those examined at 7 years. The most frequent cause of loss to follow-up was moving out of the area.

Statistical analyses for the first 4 years primarily involved multiple regression analyses of single outcomes against single alcohol predictor variables, adjusting for 
Table 1

Alcohol scores by interview sample and follow-up cohort

\begin{tabular}{|c|c|c|c|c|c|}
\hline \multirow[t]{2}{*}{ ORDEXC } & \multirow[t]{2}{*}{ Alcohol score ${ }^{a}$} & \multicolumn{2}{|c|}{ Subjects identified by each scale ${ }^{b}$} & \multicolumn{2}{|c|}{ Subjects identified by priority system } \\
\hline & & $\begin{array}{l}\text { Interview sample } \\
(n=1529)\end{array}$ & $\begin{array}{l}\text { Follow-up cohort }{ }^{d} \\
(n=582)\end{array}$ & $\begin{array}{l}\text { Interview sample } \\
(n=1529)\end{array}$ & $\begin{array}{l}\text { Follow-up cohort } \\
(n=582)\end{array}$ \\
\hline \multirow[t]{6}{*}{ High-priority $(1-6)$} & 1. $\mathrm{AA} \geq 1.0$ during & 36 & 36 & 36 & 36 \\
\hline & 2. $V V=11$ during & 26 & 26 & 5 & 5 \\
\hline & 3. $\mathrm{VV}=8$ during & 49 & 43 & 49 & 43 \\
\hline & 4. $\mathrm{AA} \geq 1.0$ prior & 110 & 106 & 66 & 64 \\
\hline & 5. $\mathrm{VV}=11$ prior & 88 & 80 & 18 & 14 \\
\hline & 6. $V V=8$ prior & 71 & 66 & 42 & 40 \\
\hline \multirow[t]{13}{*}{ Low-priority $(7-19)$} & 7. $V V=10$ during & 16 & 15 & 2 & 1 \\
\hline & 8. $V V=9$ during & 12 & 10 & 4 & 2 \\
\hline & 9. $V V=10$ prior & 46 & 39 & 11 & 6 \\
\hline & 10. $\mathrm{VV}=9$ prior & 32 & 22 & 14 & 5 \\
\hline & 11. AUP $=4$ during & 33 & 33 & 0 & 0 \\
\hline & 12. $\mathrm{AUP}=4$ prior & 109 & 100 & 0 & 0 \\
\hline & 13. QFV = 1 during & 44 & 41 & I & 0 \\
\hline & 14. $\mathrm{QFV}=1$ prior & 110 & 100 & 5 & 3 \\
\hline & 15. Intox. $\geq 5$ times & 15 & 13 & 2 & 2 \\
\hline & 16. Intox 4 times & 7 & 4 & 3 & 0 \\
\hline & 17. Intox. 3 times & 12 & 10 & 2 & 2 \\
\hline & 18. Intox 2 times & 38 & 29 & 16 & 10 \\
\hline & 19. Intox I time & 95 & 67 & 58 & 31 \\
\hline \multicolumn{2}{|l|}{ Light-moderate } & 780 & 93 & 780 & 93 \\
\hline \multicolumn{2}{|l|}{ Infrequent } & 198 & 102 & 198 & 102 \\
\hline \multicolumn{2}{|l|}{ Abstainer } & 217 & 123 & 217 & 123 \\
\hline
\end{tabular}

In 1974, ORDEXC and the alcohol scores were prioritized prior to the study according to their presumed effect on fetal welfare.

$A A \geq 1.0$ : average of at least 2 drinks per day of wine, liquor, or beer in any combination.

$\mathrm{VV}=11: 45$ or more drinks/month and 5 drinks or more on at least one occasion.

$V V=8: 17.6-44.9$ drinks/month and 5 drinks or more on at least one occasion.

$V V=10: 45$ or more drinks/month and a maximum of 3-4 drinks on at least one occasion.

$V V=9: 45$ or more drinks/month and never more than 2 drinks on any occasion.

AUP $=4: 5$ or more drinks at least 4 times a month.

$\mathrm{QFV}=1$ : a 'heavy' drinker defined by Cahalan's criteria which include average daily drinking and binge drinking.

Intox. $\geq 5$ times $=$ intoxicated 5 or more times during pregnancy.

"during = during pregnancy; "prior' = prior to pregnancy recognition

${ }^{b}$ Entries of these columns are not mutually exclusive.

'Entries of these columns are mutually exclusive. Subjects selected by higher priority codes were not eligible for selection at lower priorities.

${ }^{\mathrm{d}}$ These data derive from the full follow-up cohort of 582 described by Streissguth et al. (1993).

co-varying conditions. These methods are discussed most fully in Streissguth et al. (1986, 1989a). Analyses from 7 years forward have involved partial least squares (PLS), a method of data analysis that permits the simultaneous assessment of relations among multiple alcohol predictor scores and multiple outcome scores. PLS is better suited than multiple regression or other alternatives to complex multifactorial data generated in human behavioral teratology studies such as ours. This methodology, as applied to teratology, is described by Bookstein et al. (1990), Sampson et al. (1989) and Streissguth et al. (1989b). A recent monograph on the study (Streissguth et al., 1993) offers detailed descrip- tions of PLS analyses for cross-sectional and longitudinal designs. PLS analyses yield Latent Variables (LVs) for both dose (alcohol LVs) and response (outcome LVs) that demonstrate the salience of the prenatal alcohol scores for the outcomes under consideration. In particular, the alcohol LV, which is measured as a linear combination of all the dose measures, is very stable across diverse analyses over the whole range of ages.

Data on possible confounds were obtained prospectively, at the prenatal interview and at all succeeding waves of examination. These included maternal nutrition and use of drugs and medications during pregnancy, socio-demographic and educational character- 


\section{STUDY DESIGN \\ SEATTLE LONGITUDINAL PROSPECTIVE STUDY ON ALCOHOL AND PREGNANCY}

(prenatal through 14 years)

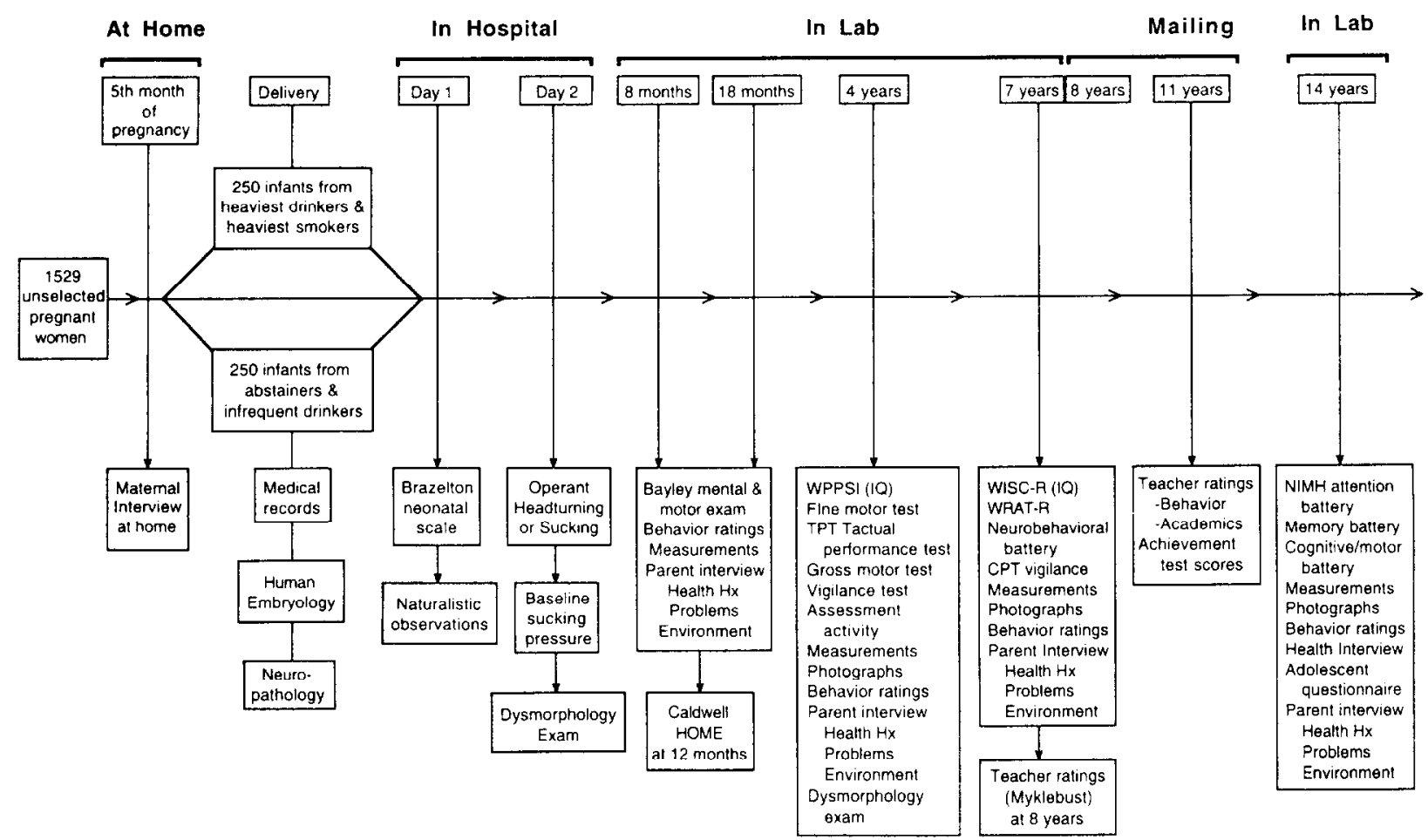

Fig. 1. Study design. The experimental design for the Seattle Longitudinal Prospective Study on Alcohol and Pregnancy. Sample sizes for substudies include the following: Brazelton, 469; naturalistic observation, 124; operant head turning, 225; operant sucking, 80; baseline sucking study. 151: neonatal dysmorphology, 163; 8-month follow-up, 468; 18-month follow-up. 496; 4-year follow-up, 465: 7-year laboratory follow-up, 486; 11 -year teacher rating study, 458; 14-year follow-up, 470 .

istics of the family, mother-child interactions, major life stresses in household, child accidents, hospitalizations and illnesses, and educational experiences of child, and so forth (Streissguth et al., 1993).

All findings reported here have been evaluated in terms of many potential confounds. First, correlations between the many covariates in the database and the outcome LVs are examined. Then the covariates that are associated with both the alcohol LV and the outcome LVs are examined in regression analyses to see to what extent they diminish the estimated effects of alcohol dose. Scatterplots and partial residual plots are routinely examined. The results reported are not attributable to other prenatal exposures such as nicotine and illicit drugs, and are not attributable to socio-demographic variables such as parental education.

\section{Results}

\subsection{Findings during infancy, preschool, and early childhood}

Infants were examined on day 1 and day 2 of life using the Brazelton Neurodevelopmental Scale (Streissguth et al., 1983); Naturalistic observations (Landesman-Dwyer et al., 1978); operant head-turning procedures, operant sucking procedures (Martin et al., 1977) and baseline sucking (Martin et al., 1979; Stock et al., 1985). Even after adjusting for delivery medications and other covariates, prenatal alcohol exposure was associated with poorer habituation. The more alcohol-exposed the infant, the more poorly did it habituate (show a response decrement) to a repetitive stimulus (Streissguth et al., 1983). Out of 474 outcomes across the first 7 years of life, habituation to light (from the Brazelton scale) was the one most correlated with prenatal alcohol exposure (Streissguth et al., 1993). Other important neonatal characteristics salient for alcohol include poorer habituation to rattle, fewer smiles, more hand-to-mouth activity, a weaker Moro reflex, hypertonic passive arms reflex, hypertonic incurvation reflex, and a delayed stepping reflex threshold (Streissguth et al., 1993).

Prenatal alcohol exposure was also associated with increased 'low arousal', a cluster of behaviors involving frequent state change at the low end of the arousal con- 
Alcohol use during pregnancy: summary statistics for drinkers only

\begin{tabular}{|c|c|c|c|c|c|c|}
\hline & $n$ & Mean & S.D. & Min. & Median & Max. \\
\hline \multicolumn{7}{|l|}{ AA: Average oz of absolute alcohol/day } \\
\hline Prepregnancy recognition & 419 & 0.81 & 1.67 & 0.01 & 0.43 & 25.76 \\
\hline During pregnancy & 445 & 0.34 & 11.62 & 0.01 & 0.16 & 8.55 \\
\hline \multicolumn{7}{|c|}{ MOCC: Monthly occasions of drinking (average) } \\
\hline Prepregnancy recognition & 419 & 16.90 & 22.00 & 0.3 & 9.0 & 240.0 \\
\hline During pregnancy & 445 & 8.48 & 12.73 & 0.3 & 4.8 & 120.0 \\
\hline \multicolumn{7}{|l|}{ QFV: Quantity-Frequency-Variability Index } \\
\hline Prepregnancy recognition & 419 & 3.55 & 1.05 & 2.0 & 3.0 & 5.0 \\
\hline During pregnancy & 445 & 3.04 & 0.95 & 2.0 & 3.0 & 5.0 \\
\hline \multicolumn{7}{|l|}{ ADOCC: Average drinks/occasion } \\
\hline Prepregnancy recognition & 419 & 2.53 & 1.47 & 1.5 & 2.2 & 13.0 \\
\hline During pregnancy & 445 & 2.20 & 1.14 & 1.5 & 1.7 & 13.0 \\
\hline \multicolumn{7}{|l|}{ MAX: Maximum drinks/any occasion } \\
\hline Prepregnancy recognition & 419 & 4.12 & 2.70 & 1.5 & 3.5 & 13.0 \\
\hline During pregnancy & 445 & 3.62 & 2.58 & 1.5 & 3.5 & 13.0 \\
\hline \multicolumn{7}{|l|}{ BINGE: 5 or more drinks on any occasion } \\
\hline Prepregnancy recognition & 419 & 0.39 & 0.49 & 0 & 0 & 1 \\
\hline During pregnancy & 445 & 0.25 & 0.43 & 0 & 0 & 1 \\
\hline ORDEXC: ordered exposure categories & 459 & 2.79 & 1.22 & 1 & 3 & 4 \\
\hline
\end{tabular}

These data derive from scores on drinkers only from the full follow-up cohort of 582 described by Streissguth et al. (1993). A high score indicates more drinking for all measures (the QFV scores have been reversed to make them compatible in direction with the other alcohol scores). Some profiles of the typical drinker in this study follow based on the median score for drinkers only. An AA score of 1.00 is equivalent to $\sim 30 \mathrm{~g}$ of alcohol/day or approximately two drinks/day of beer, or wine, or liquor. An AA of 0.43 indicates that the typical drinker in this study drank almost 1 drink of wine. beer and/or liquor a day on average prior to pregnancy recognition. An AA of 0.16 is half a drink a day on average during pregnancy. A MOCC score of 9 indicates that the typical drinker in this study drank on 9 occasions/month on average. An ADOCC score of 2.2 indicates that the typical drinker in this study reported over 2 drinks of wine. heer or liquor on average whenever she drank prior to pregnancy recognition She reported $<2$ drinks on average when she drank during pregnancy. A median MAX score of 3.5 indicates that the typical drinker in this study reported 3-4 drinks on at least one occasion during the designated time period. A BINGE score of 0 indicates that the typical drinker in this study never reported 5 or more drinks on an occasion. Thirty-nine percent of the mothers who drank had at least 5 or more drinks on at least one occasion prior to pregnancy recognition and $25 \%$ had this pattern during pregnancy. Sample size varies because Table 2 includes only those mothers who reported drinking during the designated time period. The statistics for prepregnancy recognition omit 163 mothers who abstained during that period. The during pregnancy statistics omit 137 mothers who abstained during pregnancy. The ORDEXC statistics omit 123 mothers who abstained during both time periods (total sample size for study is 582). Scores in this table are untransformed for comparative purposes even though transformed scores (as noted in the text) were used in analysis.

tinuum: for instance, alternation between awake and drowsy, or difficulty in maintaining either a good alert state or a good sleep state (Streissguth et al., 1983). Also, prenatal alcohol was associated with increased time with eyes open, bodily tremors, head turns to the left, hand to face activity, and decreased vigorous bodily activity in neonates (Landesman-Dwyer et al., 1978).

Operant learning on day 2 was decreased by exposure to alcohol only for those infants also exposed to nicotine (Martin et al., 1977). By comparison, infant sucking pressure and latency to first suck showed significant effects of prenatal alcohol exposure independent of nicotine exposure (Martin et al.. 1979). (Pressure transducer measures, obtained with a non-nutritive nipple, were more sensitive to prenatal alcohol exposure than examiner ratings of strength of the infant's sucking on the examiner's thumb, although the two were correlated (Stock et al., 1985)). The neonatal findings demonstrate that subtle central nervous system (CNS) effects of pre- natal alcohol are already measurable before the infant has ever encountered a postnatal environment.

Some authors (e.g. Coles et al., 1984) originally thought that some of the early neonatal behavioral concomitants of prenatal alcohol exposure were interpretable as manifestations of neonatal abstinence syndrome (Finnegan, 1985) (representing a drug withdrawal phenomena rather than more permanent alterations in CNS functioning). However, the persistence of alcohol-related CNS effects into childhood and adolescence precludes the conclusion that these are transient manifestations of withdrawal. Furthermore, very few of the women in this study took opiates, the drug most frequently associated with neonatal abstinence syndrome.

Retrospective examination of a subset of 7-year-olds with high alcohol exposure and deficits in 7-year neuromotor performance, revealed that they had functioned poorly at most previous assessment periods. Of all of the outcome measures, neonatal habituation and 
Table 3

Demographic characteristics of the interview sample and follow-up cohort

\begin{tabular}{|c|c|c|}
\hline & $\begin{array}{l}\text { Interview Sample } \\
(n=1529) \\
(\%)\end{array}$ & $\begin{array}{l}\text { Follow-up cohort } \\
(n=582) \\
(\%)\end{array}$ \\
\hline \multicolumn{3}{|l|}{ Maternal race } \\
\hline White & 86 & 84 \\
\hline Black & 9 & 9 \\
\hline Other & 5 & 7 \\
\hline \multicolumn{3}{|l|}{ Maternal age } \\
\hline $13-16$ & 2 & 2 \\
\hline $17-24$ & 33 & 35 \\
\hline $25-32$ & 59 & 57 \\
\hline $33-40$ & 6 & 6 \\
\hline $41-45$ & $<1$ & $<1$ \\
\hline \multicolumn{3}{|l|}{ Parity } \\
\hline Primiparous & 44 & 43 \\
\hline Multiparous & 56 & 57 \\
\hline \multicolumn{3}{|l|}{ Marital status } \\
\hline Married & 87 & 84 \\
\hline Single & 9 & 11 \\
\hline Other & 4 & 5 \\
\hline \multicolumn{3}{|l|}{ Maternal education } \\
\hline Graduate school & 7 & 7 \\
\hline College school & 25 & 20 \\
\hline Some college & 29 & 29 \\
\hline High school graduate & 28 & 29 \\
\hline Some high school & 8 & 11 \\
\hline Junior high school & 3 & 4 \\
\hline Sixth grade or less & $<1$ & 0 \\
\hline \multicolumn{3}{|l|}{ Socio-economic status } \\
\hline Upper & 10 & 9 \\
\hline Upper middle & 21 & 19 \\
\hline Middle & 27 & 24 \\
\hline Lower middle & 33 & 36 \\
\hline Lower & 9 & 12 \\
\hline \multicolumn{3}{|l|}{ Pregnancy outcome ${ }^{a}$} \\
\hline $\begin{array}{l}\text { Prematurity (gestational } \\
\text { age }<37 \text { weeks) }\end{array}$ & 4 & 4 \\
\hline $\begin{array}{l}\text { Low birthweight (BW } \\
\quad<2500 \mathrm{~g} \text { ) }\end{array}$ & 3 & 3 \\
\hline $\begin{array}{l}\text { Very low birthweight } \\
(\text { BW }<1500 \text { g) }\end{array}$ & $<1$ & 0 \\
\hline
\end{tabular}

These demographics pertain to the fifth month of pregnancy. Socioeconomic status is determined using education of the mother and occupation of the head of household, according to a modification of Hollingshead's two-factor system (Hollingshead and Redlich, 1958).

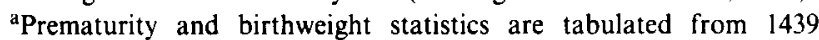
singleton born infants alive at discharge from the study hospitals, for whom delivery records were available.

7-year neuromotor function showed the strongest relationship to prenatal alcohol (Streissguth et al., 1993).

At 8 and 18 months of age, the infants were evaluated using the Bayley Scales of Infant Mental and Motor Development and various other checklists and rating scales. At 8 months, prenatal alcohol exposure was associated with small but statistically significant decrements in mental and motor development that could not be attributed to other risk factors, such as breastfeeding, maternal separation from infant, major life changes in the household, maternal diet during pregnancy, or other prenatal exposures (Streissguth et al., 1980). However, none of the 8- and 18-month scores were as strongly associated with the alcohol $\mathrm{LV}$ as those measured at birth, 4, or 7 years (Streissguth et al., 1993).

Growth parameters (height, weight, and head circumference) had shown a modest relationship to prenatal alcohol at birth. Although statistically significant, the alcohol effects were considerably smaller than the effects of smoking. By 8 months of age, the smoking effects were no longer statistically significant, while alcohol effects remained weakly significant (Barr et al., 1984). Subsequent analyses do not reveal any further associations between prenatal alcohol and height, weight, and head circumference at 18 months up through 14 years (Sampson, et al, 1994).

For the 4-year examination, a much more sensitive and comprehensive battery of neurobehavioral outcomes was assembled based on deficits observed in children with FAS who constituted a pilot study at each examination wave. As we expected, prenatal alcohol exposure was associated with statistically significant decrements on Full Scale IQ from the Wechsler Preschool and Primary Scale of Intelligence. Performance Scale IQ was more strongly predicted by prenatal alcohol than Verbal Scale IQ (Streissguth et al., 1989a). Dividing the sample at 3 drinks per day, the adjusted prenatal alcohol effect was more than -4 IQ points (one-fourth of a standard deviation). Above this level of exposure, there was a six-fold increase in offspring IQ below 85 observed in this sample. Even after adjustment for other prenatal exposures and nutrition, sociodemographic characteristics, mother-child interactions, preschool attendance, and other covariates, a three-fold risk of IQ below 85 is estimated for children of 'average background' in our population. These CNS effects of prenatal alcohol exposure were not mediated by low birthweight.

Components of the Wisconsin Motor Steadiness Battery (WMSB) and a test of Gross Motor Performance both showed significant associations with prenatal alcohol exposure at 4 years (Barr et al., 1990). On the latter test, a summary score for all balance measures was significantly associated with prenatal alcohol, although measures of coordination and distance were not. These findings may relate to reports of cerebellar signs (Marcus, 1987) or frank cerebellar dysgenesis (Clarren, 1986) reported clinically in children with FAS. Performance on grip strength, finger tapping speed, and the Tactual Performance Test (TPT) were unrelated to prenatal alcohol exposure at the 4-year examination. In working on stylus-maze tasks and motor steadiness tasks, the more alcohol-exposed children showed more time in error'. This reflects the time it takes for a child to respond to the auditory alarm by moving the stylus away 
from the inner edge of the maze when an error is made (i.e., when the edge is touched) (Barr et al., 1990).

Attention and reaction time at 4 years were measured with a Vigilance Test that produced an infrequentlyappearing target (kitty in the window) at irregular intervals (Streissguth et al., 1984a). The more alcoholexposed children more often failed to press the button to the target, more often pressed the button when no target was in sight, and took longer to press the button correctly after the target appeared (particularly at the end of testing). Behavior ratings of the children in this setting did not reveal any associations of prenatal alcohol with gross measures of activity or failure to attend physically to the stimulus. Thus, the findings seemed more related to attention difficulties than to hyperactivity. Automated measures of bodily movement in the vigilance setting were unrelated to prenatal alcohol exposure (Streissguth et al., 1984a); this may relate to the constraints upon activity in the laboratory setting.

An examiner rating of 'overall clinical impression' at the end of the 4-year neurobehavioral examination placed $19 \%$ of the children whose mothers had AA scores of at least 2.0 (4 or more drinks per day on average) in the 'suspect' or 'abnormal' categories, versus $4-5 \%$ of children in all lower levels of drinking (Streissguth et al., 1984b).

PLS analysis by wave of measurement (Streissguth et al., 1993) revealed a number of 4-year neurobehavioral effects to be among the most highly salient for the Alcohol LV. These include more 'time in error' from the WMSB, lower WPPSI IQ, lower Arithmetic and Picture Completion Subtest Scores, more frequent verbal interruptions and excessive talking during the examination. and behavior ratings (by examiner) of poorer goal directedness, poorer attention span, and more hypertonic bodily tone.

A subset of the most heavily exposed infants and hospital-matched controls was evaluated on day 1 or 2 of life for minor anomalies associated with FAS, growth deficiency, and CNS effects such as microcephaly, tremulousness, and poor suck by a dysmorphologist blind to prenatal exposures. The clinical judgement of 'fetal alcohol effects' (FAE) was associated with prenatal alcohol exposure (Hanson et al., 1978). Two infants out of this subset were identified as having FAS. At the 4-year examination, another dysmorphologist conducted blind assessments of a larger group of exposed and unexposed children (Graham et al., 1988). Eighty percent of the children identified as FAE at birth were identified as FAE at 4 years, but only $50 \%$ of those identified at 4 years had been identified at birth, suggesting that only the most obviously affected neonates will be detected at birth.

The two infants clinically identified as FAS at birth by 'blind clinical examination by a dysmorphologist experienced in FAS diagnosis have revealed interesting growth trajectories with increasing age (Sampson et al., 1994). Although they had marginally low birth weight. they were certainly not the smallest children among the 1439 births to study mothers, nor did they show the failure to thrive phenomenon that is often seen in infants with FAS. By 4 years of age they were no longer growth deficient at all and were, in fact, called only 'FAE' by the dysmorphologist conducting the 'blind' assessments at year 4 .

Their mental development during infancy revealed an uneven pattern of development: one was deviant on the 8-month Bayley Scales while the other was deviant on the Bayley MDI at 18 months. At 4 years and 7 years of age, when given the Wechsler Preschool and Primary Intelligence Scales and the Wechsler Intelligence Scale for Children - Revised, these children were both functioning in the borderline retarded range of intelligence. They have generally fallen on the low end of the many neurobehavioral and attentional tests administered between 4 years and 14 years of age, but they do not differentiate themselves as always the lowest, or even unusually low. compared with other subjects who were among the more highly exposed to alcohol in utero and who showed neurobehavioral and attentional deficits.

\subsection{School-age findings}

In the summer following their first year in school, when they averaged 7.5 years of age, the whole cohort was brought in again for a large battery of tests and measurements. Prenatal alcohol was not related to physical size at this age (Sampson et al., 1994), but facial morphology, as assessed morphometrically after digitization of facial photographs that was 'blind' to prenatal alcohol exposure. was associated with prenatal alcohol exposure in a subgroup of the most highly exposed children (Clarren et al., 1987). In comparison with the broad array of neurobehavioral outcomes associated with prenatal alcohol at this age. neither growth nor facial morphology was as sensitive a marker of a prenatal alcohol effect.

The large battery of neurobehavioral tests administered at this 7.5-year examination and their relationship to prenatal alcohol have been described in a trilogy of papers (Streissguth et al., 1989b, c; Sampson et al., 1989). We observed many deficits in spatial memory and integration, verbal memory and integration, flexible problem solving. and perceptual motor function. Verbal tasks were not as strongly affected by prenatal alcohol as were visual spatial tasks. In these analyses, we exploited PLS methods for the first time, examining multifactorial alcohol predictors in relation to multiple scores from multiple tests of neurobehavioral function.

Using data from the Wechsler Intelligence Scale for Children - Revised (WISC-R), a multiple regression analysis suggested an average 7-point decrement in Full 
Scale IQ associated with one ounce or more of average alcohol per day (mean, 50g) (Streissguth et al., 1990). Decrements of 1-3 months in Arithmetic and Reading performance on the Wide Range Achievement Test Revised (WRAT-R) were observed in association with a binge pattern of exposure. PLS analyses of the multiple alcohol predictors against the individual subtest scores of the WISC-R revealed that only certain subtests of this IQ test carried the alcohol effect (Arithmetic, Digit Span, and Block Design) while others showed little relationship to alcohol (Comprehension, Coding, Vocabulary, and Picture Assembly). The Alcohol Latent Variable (LV) most salient for these deficits in memory, problem solving, and speed of information processing emphasized a massed or 'binge' drinking pattern, particularly early in gestation.

Some behavioral ratings by the psychometrist at the conclusion of testing also revealed a pattern of association with prenatal alcohol: distractibility, overpersistence (which could also be called rigid problem solving), reassurance-seeking, and poor organization (Streissguth et al., 1989b).

During the school year following this examination, classroom teachers of this cohort of children were asked to fill out the Myklebust Pupil Rating Scale (MPRS) and to provide data on the children's functioning on standardized national achievement tests. Myklebust items that were the most salient for prenatal alcohol exposure included 'difficulty retaining information', 'lack of cooperation/impulsivity', and poorer 'comprehension of words', grammar, word recall, and tactfulness. Other associations suggest problems with focusing and maintaining attention and with processing and organization of information (Sampson et al., 1989). That is, the behavioral effects of exposure noted in the one-to-one laboratory situation were still apparent 6 months later in the ratings from second grade teachers. This generalization of findings from the narrow laboratory context to the classroom suggests that these represent intrinsic characteristics of the children, not just situationallydetermined responses.

More complex analyses (Streissguth et al., 1993) indicated that even after adjustment for potential confounds such as parental education and family size, the 7-year neurobchavioral LV was as sensitive to prenatal alcohol dose as was the best neonatal performance LV. That is, these alcohol effects are not attenuating with age.

Some of the neurobehavioral tests used at this age that were the most sensitive to prenatal alcohol exposure included: written Syntax Errors and lower Mean Length of Utterance (from the Johnson Sentence Building Test). more errors of commission on the AX task of the CPT vigilance test (reflecting impulsive errors), and lower WISC-R subtest scores of Arithmetic, Digit Span and Block Designs, and lower WRAT-R Arithmetic and Spelling Achievement Scores (Streissguth et al., 1993).
Across the ages from 1 day to 7 years there thus emerges a wide diversity of deficits induced by prenatal alcohol exposure. Among the most salient sequelae of exposure are neonatal habituation to light (from the Brazelton scale administered on day 1 of life); speed of information processing at age 4 (measured by the time taken to correct errors on a visual-spatial task, the Wisconsin Motor Steadiness Battery); standardized assessments of arithmetic performance following the first year in school (as measured by both the WISC-R Arithmetic subtest and the WRAT-R achievement test); and academic performance as measured by the secondgrade teacher ratings. For most of these outcomes, binge drinking has more serious consequences than the same amount of steady drinking, and drinking early in pregnancy has more serious consequences than the same reported pattern of drinking in mid-pregnancy. There is no statistical evidence for a 'risk-free' or threshold level of prenatal drinking; and these alcohol effects cannot be 'explained away' by any of 150 covariates considered, including parents' education, maternal smoking and nutrition during pregnancy (Streissguth et al., 1993).

\subsection{Late childhood and adolescent findings}

When the children were 11 years old, we again mailed questionnaires to their schools. The Multigrade Inventory for Teachers (MIT) and the MPRS were also related to prenatal alcohol in profiles reminiscent of those for findings with earlier teacher ratings. Behaviors that were the most salient for prenatal alcohol exposure in the cohort at 11 years included distractibility, restlessness, lack of persistence, and reluctance to meet challenges. Learning problems showing the greatest salience for prenatal alcohol exposure included those measuring information-processing and reasoning problems and a lack of interest in reading. On standardized national achievement tests, arithmetic performance was the most affected by prenatal alcohol exposure, followed closely by the 'total achievement' scores (Carmichael Olson et al., 1992).

The newest findings from the Seattle study involve data from assessments of the cohort at 14 years of age, when $82 \%$ of the original cohort were again evaluated (Streissguth et al., 1994a, b; Sampson et al., 1994). Arithmetic (from the WISC-R) is again highly salient for prenatal alcohol exposure, and by now a longitudinal component is clear: $91 \%$ of the heavier drinkers' children who had scored low on Arithmetic at 7 years, remained low on Arithmetic at 14 years (versus only $45 \%$ of the abstainers' children who had scored low on Arithmetic at 7 years). Findings such as these, going beyond correlational analyses, suggest that these deficits are not a transient response to characteristics of the testing situation, but rather reflect some ongoing compromise of the CNS function not ameliorated by ordinary remedial programming. There are also significant effects of prenatal alcohol upon a measure of phonological process- 
ing, the Word Attack Subtest of the Woodcock Johnson Battery (Streissguth et al., 1994a).

There are continued alcohol-related deficits upon attention/memory scores, especially measures of fluctuating attentional states (observed in increased individual variability in reaction time), problems with response inhibition (assessed with increased error and 'false alarm' rates on attentional tasks including the Talland Letter Cancellation Test and the Continuous Performance Test [CPT]); and spatial learning deficits (assessed with a computerized adaptation of Milner's Stepping Stone Maze [SSM]) (Streissguth et al., 1994b). A latent variable reflecting the pattern of attention/memory deficits observed at 14 years correlated 0.67 with the composite pattern of 7-year neurobehavioral fetal alcohol effects. The same binge-weighted pattern of prenatal alcohol exposure salient for 7-and 11-year neurobehavioral outcomes was still evident in the 14-year data.

Longitudinal analyses of vigilance test performance at 4-, 7-, and 14-year examinations indicate some continuities of deficit across this 10 -year period of child development. The 19 poorest performers on the CPT at 14 years had all been poorer than average on the CPT at 7 years. Forty-seven percent of these had also been given poor ratings on attention by 2 nd grade teachers, versus $18 \%$ of the rest of the sample. Sixty-six percent of the poor vigilance performers at 14 years had previously been given poor or below average ratings on attention by 11 th grade teachers (versus only $26 \%$ for the rest of the sample).

\section{Discussion}

Growth, morphology, and CNS dysfunction are the three primary channels of measurement for human teratology research in living offspring. These are also the three primary characteristics diagnostic for fetal alcohol syndrome. At the level of exposure observed in this cohort, alcohol does not exert a reliable and measurable effect on physical growth in the young adolescent (Sampson et al., 1994). Dysmorphic facial features detected only among the most highly exposed offspring at 7 years (Clarren et al., 1987) appear weaker and more variable by age 14 . These findings are consistent with studies of children with FAS as they approach adolescence (Streissguth et al., 1991; Spohr et al., 1993), when the facial features are often clinically less remarkable. In the Seattle Study, only the neurobehavioral outcomes, documented in this cohort since day 1 of life, have continued to show significant associations with prenatal alcohol up to 14 years of age (Streissguth et al., 1993. 1994a, b).

The critical role of alcohol in producing these longterm deficits is substantiated by a growing number of studies from the experimental animal literature, where the etiologic role of alcohol can clearly be separated from those of competing hypotheses such as nutrition, rearing conditions, and so forth. Although 15 years ago the focus of animal alcohol teratology research was on the chronic maternal alcoholism model with heavy dosing throughout pregnancy, more recent studies are exploring effects of lower doses, binge patterns, and specific timing of the prenatal alcohol effect (Streissguth et al., 1993). Studies of laboratory animals have demonstrated long-term neurobehavioral deficits in many arenas of performance, even at levels of dose and pattern of alcohol exposure that do not produce growth or morphologic changes (Riley, 1990). Additional animal studies investigating increasingly lower-dose models have shown long-term neurochemical effects in the brain that are not reflected in gross structural brain defects. but which nevertheless interfere with normal information processing in the mature animal (e.g.. Goodlett and West, 1992).

Findings from our study are congruent with early studies such as those by Ouellette et al. (1977). Sander et al. (1977), and Scher et al. (1988) which demonstrated effects of prenatal alcohol exposure on newborn arousal. More recent research on infants, using more sophisticated methods than ours. has replicated the small early developmental decrements we observed on the Bayley scales (Jacobson et al.. 1993a) and has expanded downward into the infancy period the finding of decrements on sensitive tasks of speed of information processing (Jacobson et al.. 1993b).

Not all studies detect early neurobehavioral effects of prenatal alcohol (Ernhart et al.. 1985: Richardson et al., 1989). Differences in outcome can be accounted for by differences in study design. success of follow-up, sensitivity of outcome measures, presence of other risk factors. and so forth. Studies that have attempted to use general scales of infant development (such as the Bayley scales) as the primary outcome for prenatal alcohol effects at later developmental ages, have often met with disappointment. The present study is no exception. Our 18-month Bayley examination failed to reveal prenatal alcohol effects (Streissguth et al., 1993). As we found many significant infant and child outcomes associated with prenatal alcohol both before and after the 18month age, it may be that general developmental scales are simply not sensitive cnough to capture the subtle CNS effects associated with prenatal alcohol at this particular developmental age. Perhaps the variable emergence of language plays an important role in obscuring the alcohol-related deficits that seem to be reliably measured at other ages. Affirmations of the null hypothesis deriving from studies that terminate at this age, and/or fail to use sensitive outcomes, would appear to be unwarranted. Readers wishing a fuller review of recent research in the arena of alcohol effects on human development may wish to consult Coles (1992). Day (1992), Russell et al. (1991), and Streissguth et al. (1993). 


\section{Conclusion}

This longitudinal prospective study of a large birth cohort of offspring has found that the most enduring effects of prenatal alcohol exposure, at the level of exposure manifested in this population-bascd study, are on neurobehavioral function. Partial least squares (PLS) methods of data analysis have permitted consideration of multiple measures of alcohol dose and of multiple neurobehavioral outcomes. Potential confounding variables have been examined with multiple regression techniques; the results reported here are not attributable to other teratogenic exposures, smoking, or social/demographic variables. Neurobehavioral effects of prenatal alcohol were observed from the first day of life through 14 years. These effects were dose-dependent, generally without a threshold, and, in the school-age years, more salient for binge-type drinking patterns. Self-reported drinking prior to pregnancy recognition generally is more salient for these outcomes than drinking in mid-pregnancy, but the two are highly correlated. Learning problems, particularly for arithmetic, were observed from 7 through 14 years, but problems with attention and speed of information processing were observable across the 14-year period.

\section{Acknowledgments}

This research has been primarily supported by U.S. Public Health Service, grant no. AA0145501-20 from the National Institute of Alcohol Abuse and Alcoholism, with supplemental support from the University of Washington Alcoholism and Drug Abuse Institute, the University of Washington Biomedical Research Support Grant, the National Council on Alcoholism, and private contributions. The contributions of original coinvestigators, Drs. Joan C., and Donald C. Martin, and of Drs. Ruth E. Little, Heather Carmichael Olson, Betty Darby, and Sterling K. Clarren, are gratefully acknowledged, as is the technical assistance of Pam J. Phipps, Cara C. Ernst, and Sue Lippek. We thank the children and families whose loyal support has made this study possible.

\section{References}

Barr, H.M., Streissguth, A.P., Martin, D.C. and Herman, C.S. (1984) Infant size at 8 months of age: relationship to maternal use of alcohol, nicotine, and caffeine during pregnancy. Pediatrics 74 , $336-341$

Barr, H.M., Streissguth, A.P., Darby, B.L. and Sampson, P.D. (1990). Prenatal exposure to alcohol, caffeine, tobacco, and aspirin: effects on fine and gross motor performance in 4-year-old children. Dev. Psychol. 26, 339-348.

Bookstein, F.L., Sampson. P.D., Streissguth, A.P. and Barr, H.M. (1990). Measuring 'dose' and 'response' with multivariate data using partial least squares techniques. Commun. Stat. 19, 765-804.

Cahalan, D., Cissin, I.H. and Crossley, H.M. (1969) American Drink- ing Practices: A National Study of Drinking Behavior and Attitudes, Monograph 6. Rutgers Center of Alcohol Studies Publications, New Brunswick, NJ.

Carmichael Olson, H., Sampson. P.D.. Barr. H.. Streissguth. A.P. and Bookstein, F.L. (1992) Prenatal exposure to alcohol and school problems in late childhood: a longitudinal prospective study. Dev. Psychopathol. 4, 341-359.

Clarren, S.K. (1986) Neuropathology in fetal alcohol syndrome. In: Alcohol and Brain Development (West, J.R., ed.) pp. 158-166. Oxford University Press. New York.

Clarren, S.K., Sampson, P.D., Larsen, J., Donnell, D.J., Barr, H.M., Bookstein, F.L., Martin. D.C. and Streissguth, A.P. (1987) facial effects of fetal alcohol exposure: assessment by photographs and morphometric analysis. Am. J. Med. Genet. 26, 651-666.

Coles, C.D. (1992) Prenatal alcohol exposure and human development. In: Development of the Central Nervous System: Effects of Alcohol and Opiates (Miller. M.W., ed.), pp. 9-36. Wiley-Liss. New York.

Coles, C.D., Smith, I.E., Fernhoff, P.M. and Falek, A. (1984) Neonatal ethanol withdrawal: characteristics in clinically normal nondysmorphic neonates. J. Pediatr. 105, 445-451.

Day, N.L. (1992) Effects of prenatal alcohol exposure. In: Maternal Substance Abuse and the Developing Nervous System (Zagon, I.S. and Slotkin, T.A., eds.) pp. 27-43. Academic Press, San Diego.

Ernhart, C.B., Wolf, A.W., Linn, P.L., Sokol, R.J., Kennard, M.J. and Filipovich, H.F. (1985) Alcohol-related birth defects: syndromal anomalies, intrauterine growth retardation, and neonatal behavioral assessment. Alcohol Clin. Exp. Res. 9, 447-53.

Finnegan, L.P. (1985) Neonatal Abstinence. In: Current Therapy in Neonatal-Perinatal Medicine, 1985-1986 (Nelson. N.M., ed.) pp 262-270. C.V. Moseby, St. Louis.

Goodlett, C.R. and West, J.R. (1992) Fetal alcohol effects: Rat model of alcohol exposure during the brain growth spurt. In: Maternal Substance Abuse and the Developing Nervous System (Zagon, I.S. and Slotkin, T.A., eds.) pp. 45-75. Academic Press, San Diego.

Graham, J.M. Jr, Hanson, J.W., Darby, B.L., Barr, H.M. and Streissguth, A.P. (1988) Independent dysmorphology evaluations at birth and 4 years of age for children exposed to varying amounts of alcohol in utero. Pediatrics 81, 772-778.

Hanson, J.W., Streissguth, A.P. and Smith, D.W. (1978) The effects of moderate alcohol consumption during pregnancy on fetal growth and morphogenesis. J. Pediatr. 92, 457-460.

Hollingshead, A.B. and Redlich, F.C. (1958) Social Class and Mental Illness, A Community Study. John Wiley, New York

Jacobson, J.L., Jacobson, S.W., Sokol, R.J., Martier, S.S., Ager, J.W. and Kaplan-Estrin, M.G. (1993a) Teratogenic effects of alcohol on infant development. Alcohol Clin. Exp. Res. 17, 174-183.

Jacobson, S.W., Jacobson, J.L., Sokol, R.J., Martier, S.S. and Ager. J.W. (1993b). Prenatal alcohol exposure and infant information processing ability. Child Dev. 64, 1706-1721

Jones, K.L. and Smith, D.W. (1973) Recognition of the Fetal Alcohol Syndrome in early infancy. Lancet ii, 999-1001.

Jones, K.L., Smith, D.W., Ulleland, C.N. and Streissguth, A.P. (1973) Pattern of malformation in offspring of chronic alcoholic mothers. Lancet i, 1267-1271.

Jones, K.I., Smith, D.W., Streissguth, A.P. and Myrianthopoulos. N.C. (1974). Outcome in offspring of chronic alcoholic women. Lancet i, 1076-1078.

Landesman-Dwyer, S., Keller, L.S. and Streissguth, A.P. (1978) Naturalistic observations of newborns: effects of maternal alcohol intake. Alcohol Clin. Exp. Res. 2, 171-177.

Lemoine. P., Harousseau. H.. Borteyru, J.P. and Menuet, J.C. (1968) Les enfants de parents alcooliques: anomalies observees. A propos de 127 cas. Ouest Med. 21, 476-482.

Marcus, J.C. (1987) Neurological findings in the Fetal Alcohol Syndrome. Neuropediatrics 18, 158-160.

Martin, J.C., Martin, D.C., Lund, C.A. and Streissguth, A.P. (1977) 
Maternal alcohol ingestion and cigarette smoking and their effects on newborn conditioning. Alcohol Clin. Exp. Res. 1, 243-247.

Martin. D.C., Martin, J.C., Streissguth, A.P. and Lund, C.A. (1979) Sucking frequency and amplitude in newborns as a function of maternal drinking and smoking. In: Currents in Alcoholism, Vol. 5 (Galanter. M., ed.), pp. 359-366. Grune \& Stratton, New York.

Ouellette, L.M., Rosett, H.L., Rosman. N.P. and Weiner, L. (1977) Adverse effects on offspring of maternal alcohol abuse during pregnancy. N. Engl. J. Med. 297, 528-530.

Richardson, G.A.. Day, N.L. and Taylor, P.M. (1989) The effect of prenatal alcohol, marijuana, and tobacco exposure on neonatal behavior. Infant Behav. Dev. 12, 199-209.

Riley, E.P. (1990) The long-term behavioral effects of prenatal alcohol exposure in rats. Alcohol Clin. Exp. Res. 14, 670-673.

Russell. M. (1991) Clinical implications of recent research on the fetal alcohol syndrome. Bull. N.Y. Acad. Med. 67. 207-222.

Sampson, P.D.. Streissguth, A.P.. Barr, H.M. and Bookstein, F.L. (1989) Neurobehavioral effects of prenatal alcohol. Part II: partial least squares analysis. Neurotoxicol. Teratol. 11, 477-491.

Sampson, P.D., Bookstcin. F.L., Barr, H.M. and Streissguth. A.P. (1994) Prenatal alcohol exposure, birthweight, and measures of child size from birth to age 14 years. Am. J. Public Health 84. $1421-1428$

Sander. L.W.. Snyder, P.A.. Rosett, H.L., Lee, A.. Gould, J.B. and Ouellette, E. (1977) Effects of alcohol intake during pregnancy on newborn state regulation: a progress report. Alcohol Clin. Exp. Res. 1, 233-241.

Scher, M.S., Richardson, G.A., Coble, P.A., Day, N.L. and Stoffer, D.S. (1988) The effects of prenatal alcohol and marijuana exposure: disturbances in neonatal sleep cycling and arousal. Pediatr. Res. 24. $101-105$

Spohr H.L., Willms, J. and Steinhausen, H.C. (1993) Prenatal alcohol exposure and long-term developmental consequences. Lancet. 341. $907-910$.

Stock, D.L., Streissguth, A.P. and Martin, D.C. (1985) Neonatal sucking as an outcome variable: comparison of quantitative and clinical assessments. Early Hum. Dev. 10, 273-278.

Streissguth, A.P. and Giunta, C.T. (1992) Subject recruitment and retention for longitudinal research: practical considerations for a nonintervention model. In: Methodological Issues in Epidemiological, Prevention, and Treatment Research on Drugexposed Women and Their Children, National Institute on Drug Abuse Monograph 117 (Kilbey. M.M. and Asghar, K., eds.). U.S. Department of Health and Human Services, Rockville, MD.

Streissguth, A.P., Barr. H.M., Martin. D.C. and Herman, C.S. (1980) Effects of matcrnal alcohol, nicotine and caffeine use during pregnancy on infant mental and motor development at 8 months. Alcohol Clin. Exp. Res. 4, 152-164.

Streissguth. A.P., Martin, D.C., Martin J.C. and Barr H.M. (1981) The Seattle longitudinal prospective study on alcohol and pregnancy. Neurobehav. Toxicol. Teratol. 3, 223-233

Streissguth. A.P., Barr. H.M. and Martin. D.C. (1983) Maternal alco- hol use and neonatal habituation assessed with the Brazelton Scale. Child Dev. 54, 1109-1118.

Streissguth, A.P., Martin, D.C., Barr, H.M.. Sandman, B.M., Kirchner, G.L. and Darby, B.L. (1984a) Intrauterine alcohol and nicotine exposure: Attention and reaction time in 4-year-old children. Dev. Psychol. 20, 533-541.

Streissguth, A.P., Barr, H.M. and Martin, D.C. (1984b) Alcohol exposure in utero and functional deficits in children during the first four years of tife. In: Mechanisms of Alcohol Damage In Utero, CIBA Foundation Symposium 105, pp. 176-196. Pitman. London.

Streissguth, A.P., Sampson, P.D., Barr, H.M., Clarren. S.K. and Martin, D.C. (1986) Studying alcohol teratogenesis from the perspective of the Fetal Alcohol Syndrome: methodological and statistical issues. In: Mental Retardation: Research, Education, and Technology Transfer, Vol. 477 (Wisniewski, H. and Snider. D.A., eds.). pp. 6.3-86. New York Academy of Sciences. New York.

Streissguth. A.P., Barr, H.M., Sampson, P.D., Darby, B.L. and Martin, D.C. (1989a) IQ at age four in relation to maternal alcohol use and smoking during pregnancy. Dev. Psychol. 25, 3-11.

Streissguth, A.P., Bookstein. F.L., Sampson, P.D. and Barr. II.M. (1989b) Neurobehavioral effects of prenatal alcohol. Part III: PLS analyses of neuropsychologic tests. Neurotoxicol. Teratol. 11. 493-507.

Streissguth, A.P., Barr, H.M., Sampson. P.D., Bookstein, F.L. and Darby, B.L. (1989c). Neurobehavioral effects of prenatal alcohol. Part I: research strategy. Neurotoxicol. Teratol. 11. 461-476.

Streissguth. A.P.. Barr. H.M. and Sampson. P.D. (1990) Moderate prenatal alcohol exposure: effects on child $I Q$ and learning problems at age 71/2 years. Alcohol Clin. Exp. Res. 14, 662-669.

Streissguth. A.P.. Aase. J.M.. Clarren. S.K., Randels, S.P., LaDue. R.A. and Smith, D.F. (1991) Fetal Alcohol Syndrome in adolescents and adults. J. Am. Med. Assoc. 265, 1961-1967.

Streissguth, A.P.. Bookstein, F.L.. Sampson. P.D. and Barr. II.M. (1993) The Enduring Effects of Prenatal Alcohol Exposure on Child Development. Birth Through 7 Years: A Partial Least Squares Solution. University of Michigan Press, Ann Arbor, MI.

Streissguth. A.P., Barr, H.M.. Carmichael Olson. H.. Sampson, P.D.. Bookstein. F.L. and Burgess. D.M. (1994a) Drinking during pregnancy decreases word attack and arithmetic scores on standardized tests: adolescent data from a population-based prospective study Alcohol Clin. Exp. Res. 18, $248-254$.

Streissguth, A.P. Sampson, P.D., Carmichael Olson, H., Bookstein, F.L.. Barr. H.M.. Scott. M.. Feldman, J. and Mirsky, A.F. (1994b) Maternal drinking during pregnancy: Attention and short-term memory in 14-year-old offspring .... i longitudinal prospective siudy. Alcohol Clin. Exp. Res. 18, 202-218.

Wilson, J.G. (1977) Current status of teratology: General principles and mechanisms derived from animal studies. In: Handbook of Teratology, Vol. 1: General Principles and Etiology (Wilson, J.G. and Fraser. F.C., eds.), pp. 47-74. Plenum Press. New York and L.ondon. 